\title{
O PROBLEMA DA TÉCNICA EM HABERMAS
}

\author{
Clístenes Chaves de França ${ }^{1}$
}

\begin{abstract}
Resumo:
O trabalho tem por objetivo discutir o problema da técnica em Jürgen Habermas. Ele mostra como o filósofo alemão supera a crítica de Marcuse à técnica e à ciência como manifestações ideológicas de uma classe social historicamente situada, ao mesmo tempo que vincula ambas à racionalidade teleológica que estaria incrustada no desenvolvimento da espécie humana. Por meio das categorias trabalho e interação, Habermas aponta para o os riscos da colonização dos espaços de interação social pela racionalidade instrumental e defende que a construção de uma sociedade emancipada só será possível se os espaços reservados à racionalidade comunicativa forem protegidos contra toda forma de coisificação.
\end{abstract}

Palavras-chave: Habermas. Técnica. Ciência. Racionalidade Instrumental. Racionalidade Comunicativa.

\section{THE PROBLEM OF TECHNICS IN HABERMAS}

\begin{abstract}
:
The paper aims to discuss the problem of technology in Jürgen Habermas. It shows how the German philosopher overcomes Marcuse's criticism of technology and science as ideological manifestations of a historically situated social class, while linking both to the teleological rationality that is embedded in the development of the human species. Through the categories of work and interaction, Habermas points to the risks of colonization of the sphere of social interaction by instrumental rationality and argues that the construction of an emancipated society will only be possible if the sphere reserved for communicative rationality is protected against all forms of reification.
\end{abstract}

Key words: Habermas. Technology. Science. Instrumental Rationality. Communicative Rationality.

\section{Introdução}

Em seu ensaio sobre a ciência e a técnica ${ }^{2}$ escrito no final dos anos sessenta, Habermas defronta-se com a leitura feita por Marcuse que identifica na técnica e ciência $^{3}$ modernas um conteúdo ideológico de legitimação política da dominação de

1 Doutor em Filosofia pela Universidade Federal do Ceará (2017). Professor dos cursos de Direito e Administração da Faculdade Luciano Feijão e do Curso de Direito da Faculdade Ieducare. E-mail: clisteneschaves@hotmail.com.

2 A técnica engloba os mecanismos criados pelo ser humano para se apropriar do mundo natural e satisfazer suas necessidades. "O homem é um ser natural que para sustentar sua existência necessita apropriar-se de bens naturais, o que ele faz por sua intervenção no mundo, cuja possibilidade só é possível [sic] mediante certos mecanismos por ele criados, os quais lhe permitem exercer seu trabalho, dominar, manipular, o meio natural, colocá-lo ao seu serviço. A esses mecanismos chamamos técnica" (OLIVEIRA, 2012, p. 66, grifo do autor).

3 Puentes nos lembra que inicialmente os termos gregos téchne e epistéme eram estreitamente relacionados: "[. . . e é sempre oportuno lembrar que o espectro semântico recoberto pelo termo grego téchne é muito mais abrangente do que o que a sua tradução mais usual, arte, significa para nós. Isto ocorre porque ele não se refere apenas e tão somente à habilidade ou destreza de um especialista qualificado capaz de produzir com maestria algum artefato, mas também a uma dimensão teórica e especulativa. Em outras palavras, a téchne, portanto, é para os gregos uma forma de conhecimento. Essa relação estreita entre a téchne, por um lado, e o conhecimento teórico, por outro, é o que explica 
classe presente no sistema capitalista de produção e distribuição da riqueza. Para Marcuse, há uma confusão deliberada entre a ideia de racionalização moderna e a construção de um projeto político de dominação social. O sistema capitalista, nas sociedades industriais avançadas, proporciona uma nova fundamentação para a legitimação de seu domínio sobre os indivíduos e os processos naturais: ele apresenta essa dominação como expressão de um aumento de racionalidade na administração do processo de produção e distribuição dos bens e serviços. A contrapartida do sistema que o leva a cooptar as massas para a aceitação dessa nova forma de dominação é o oferecimento de uma vida mais confortável aos indivíduos. A dominação política é escamoteada sob os signos do "progresso", “desenvolvimento", "racionalização", ou seja, a dominação política é confundida com a própria ideia de evolução da vida humana. $^{4}$

Marcuse vê no atrelamento entre o desenvolvimento das forças produtivas e o progresso técnico-científico uma desvirtuação da ideia de racionalidade. Esta perde o seu conteúdo crítico e emancipatório de contestação e denúncia de todas as formas de dominação e exploração, passando a ser identificada como expressão da própria organização institucional do processo produtivo. A racionalidade passa a servir como elemento de legitimação da dominação vigente em um sistema tido agora como expressão e produto da aplicação da própria racionalidade às forças produtivas.

Nesse sentido, o quadro institucional que organiza o processo de dominação e exploração é apresentado como desprovido de valor político, pois é tido como produto de uma forma neutra de racionalidade que otimiza funcionalmente o processo de produção da riqueza e, consequentemente, de distribuição das recompensas sociais daquela advindas. A organização social é entendida, portanto, como tecnicamente legitimada e, assim, neutra do ponto de vista político, pois racionalmente instituída. ${ }^{5}$

Uma legitimação técnico-científica do marco institucional inviabiliza críticas ao modelo de produção estabelecido, permitindo unicamente que se proceda a correções técnicas dentro do próprio sistema. O único debate ainda tolerado restringe-se

e fundamenta a intercambialidade dos termos téchne (arte) e epistéme (ciência) durante todo o século V a.C" (PUENTES, 1998, p. 129, grifos do autor).

4 “'O domínio tem uma razão para ser 'aceito' pelos indivíduos, pois lhes proporciona uma vida mais confortável. Esta é uma das justificativas que o novo modo de dominação apresenta para adquirir aceitação e legitimidade" (DINIZ, 2012, p. 241).

5 Esta circunstância legitima a conclusão de que "[. . . ] a técnica passou a ocupar o lugar da política e esta perde significado ao dirimir seu significado no sentido da técnica" (SILVA; SILVA, 2012, p. 78).

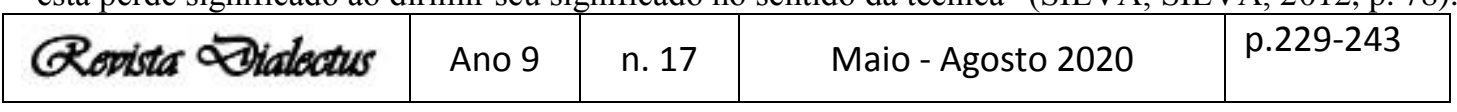


à escolha entre modelos alternativos de otimização do sistema, expressão este que é da própria racionalidade.

Marcuse lê na lógica e critérios de emprego da ação racional com relação a fins o a priori de uma dominação e controle dos processos naturais e a utilização deste para o controle e dominação entre os seres humanos. Com isso, a ciência e a técnica (tecnologia) por corporificarem as formas mais desenvolvidas da racionalidade teleológica (instrumental) seriam expressões máximas das ideias de dominação e controle presentes no modo de produção capitalista. ${ }^{6}$ Ciência e técnica, e consequentemente a racionalidade que as sustenta, além dos critérios da ação controlada pelo êxito que as impulsiona não seriam, ao contrário do que se acredita, axiologicamente neutros. Ciência e técnica assumiriam uma lógica de controle e eliminação da liberdade, o que levaria a uma maior subjugação do humano ao nãohumano; mascarariam a dominação política historicamente construída como lógica das coisas, como respeito a meros processos que se desenrolam naturalmente. Este, portanto, seria o seu conteúdo ideológico.

Dominação e falta de liberdade passam a ser entendidas não mais como expressão de escolhas políticas ou irracionalidade, mas antes como produtos anódinos do respeito à lógica mesma das coisas e dos processos naturais. As recompensas resultantes, que aparecem na forma de ampliação da comodidade da vida e aumento da produtividade do trabalho, são utilizadas para a legitimação da institucionalidade que sustenta o sistema produtivo o qual naturaliza a exploração humana e da natureza.

\begin{abstract}
A ‘racionalização' de Max Weber [para Marcuse] não é apenas um processo a longo prazo da modificação das estruturas sociais, mas também ao mesmo tempo 'racionalização' no sentido de Freud: o verdadeiro motivo, a manutenção da dominação objetivamente caduca, é ocultado pela invocação de imperativos técnicos. Semelhante invocação é possível só porque $a$ racionalidade da ciência e da técnica já é na sua imanência uma racionalidade do dispor, uma racionalidade da dominação (HABERMAS, 2006, p. 49, grifos nossos).
\end{abstract}

A ciência e a técnica servem perfeitamente ao projeto de dominação política que impede a emancipação humana, porque a racionalidade que as impulsiona - aquela que vincula, da forma mais eficiente possível, meios e fins - é, em si mesma, uma racionalidade da dominação.

6 Como veremos adiante, Habermas criticará Marcuse exatamente por entender sua leitura historicizante da racionalidade técnico-científica como altamente restritiva.

\begin{tabular}{|l|l|l|l|l|}
\hline Revista Dialectus & Ano 9 & n. 17 & Maio-Agosto 2020 & p.229-243 \\
\hline
\end{tabular}


A historicização da lógica interna à ação racional com relação a fins, que sustenta a ciência e técnica modernas, identificando-a como serva de interesses de classe específicos, leva Marcuse a conceber que o ideal de emancipação humana, isto é, de libertação em relação a todas as formas de exploração e dominação socialmente construídas, exigiria para a sua realização uma transformação da própria natureza da técnica e ciência tal como estas existem hoje. ${ }^{7}$ Isso implicaria a produção de uma nova ciência que teria que descrever de forma diferente a realidade objetiva por meio da construção (invenção) de novos conceitos, estes não mais comprometidos com qualquer possibilidade de dominação da natureza ou do ser humano.

Assim, a realidade descrita por uma ciência emancipada, ou a serviço da emancipação humana, seria conceitualmente incomensurável com a realidade descrita pela ciência moderna. A experiência com a realidade possibilitada por tal ciência seria categorialmente distinta da que hoje nos é oferecida pela ciência, na medida em que esta última se encontra inserida no quadro transcendental da ação instrumental que objetiva a realidade do ponto de vista de sua disposição técnica. Uma ciência emancipada, por exemplo, poderia possibilitar um contato com a natureza regido pelos signos do cuidado, reconhecimento e respeito.

\section{A crítica de Habermas à interpretação de Marcuse da técnica e da ciência}

Habermas é fundamentalmente cético em relação a essa leitura feita por Marcuse da ciência e técnica modernas como expressão dos interesses de classe existentes em um momento historicamente determinado.

[. . .] a ciência moderna só se podia conceber como um projeto historicamente sem precedentes se, pelo menos, fosse pensável um projeto alternativo e, além disso, uma nova ciência alternativa deveria incluir a definição de uma nova técnica. Uma tal consideração desanima-nos, já que a técnica, se em geral pudesse reduzir-se a um projeto histórico, teria evidentemente de conduzir a um 'projeto' do gênero humano no seu conjunto, e não um projeto historicamente superável (HABERMAS, 2006, p.51).

Para Habermas, há uma ligação imanente e, portanto, indissolúvel entre a técnica e a "estrutura da ação racional dirigida a fins". Esta, por sua vez, liga-se ao desenvolvimento natural da espécie, que possibilitou ao ser humano a superação dos

7 “[...] no capitalismo, é a máquina autonomizada que se serve do homem e o substitui; em vez da tecnologia ser subordinada e controlada pelo homem, é ela que o controla" (CHAGAS, 2012, p.141).

\begin{tabular}{|l|l|l|l|l|}
\hline Gevista Dialectus & Ano 9 & n. 17 & Maio - Agosto 2020 & p.229-243 \\
\hline
\end{tabular}


obstáculos enfrentados para a sua autoconservação. A técnica seria produto da ampliação e aperfeiçoamento das trocas metabólicas existentes entre nossa espécie e a natureza na luta pela sobrevivência. Nesse sentido, como expressão da ação racional em relação a fins, ou seja, como expressão da ação racional teleológica, a técnica estaria inscrita na própria constituição da espécie humana. Uma outra técnica demandaria outra espécie humana, que não precisasse relacionar-se com a natureza para extrair desta sua sobrevivência.

\footnotetext{
Se [. . .] se tem presente que a evolução técnica obedece a uma lógica que corresponde à estrutura da ação racional teleológica e controlada pelo êxito e isto significa: à estrutura do trabalho - então, não se vê como poderíamos renunciar à técnica, isto é, à nossa técnica, substituindo-a por uma qualitativamente distinta, enquanto não se modificar a organização da natureza humana e enquanto houvermos de manter a nossa vida por meio do trabalho social e com a ajuda dos meios que substituem o trabalho (HABERMAS, 2006, p.52).
}

A técnica, tal como existe hoje (como forma de controle e dominação pelo trabalho dos processos naturais), não é substituível por uma outra técnica não dominadora. Segundo Habermas, a defesa feita por Marcuse de uma atitude diferente para com a natureza, uma que nos levasse a reconhecê-la como um outro sujeito com o qual pudéssemos nos comunicar, isto é, da qual toda e qualquer possibilidade de dominação e exploração fossem excluídas, esta atitude essencialmente comunicativa para com a natureza não poderia construir uma outra técnica. Dessa atitude não se poderia extrair técnica alguma, haja vista que a lógica que rege a ação comunicativa é irredutível à lógica que rege a ação instrumental. Na medida em que a técnica é indissociável da ação teleológica não seria factível a construção de uma outra fundada comunicativamente, apesar da defesa em contrário feita por Marcuse.

Habermas considera, portanto, que não há alternativa à ciência e técnica modernas, pois ambas são projeções necessárias da forma como a espécie humana garante sua sobrevivência enquanto espécie em sua relação com a natureza. Ambas estão regidas pelo signo da disposição instrumental da natureza. A irredutibilidade da lógica que subjaz ao trabalho - lógica instrumental - à lógica que subjaz à interação -

\begin{tabular}{|l|l|l|l|l|}
\hline Gevista Dialectus & Ano 9 & n. 17 & Maio - Agosto 2020 & p.229-243 \\
\hline
\end{tabular}


lógica comunicativa ${ }^{8}$ - bloqueia ao nível mesmo das categorias, o projeto de técnica e ciência alternativas insinuado por Marcuse.

Essas considerações feitas por Habermas o levam a contrapor-se à interpretação reducionista de Marcuse da ciência e técnica como meras expressões de interesses de classe historicamente determinados e limitados.

\begin{abstract}
A alternativa à técnica existente, o projeto de uma natureza como interlocutor em vez de objeto, refere-se a uma estrutura alternativa da ação: à interação simbolicamente mediada, que é diferente da ação racional teleológica. Mas isto quer dizer que os dois projetos são projeções do trabalho e da linguagem, projetos, pois do gênero humano na sua totalidade, e não de uma época singular, de uma classe determinada ou de uma situação ultrapassável (HABERMAS, 2006, p.53).
\end{abstract}

Técnica e ciência não devem ser tidas como realização do projeto de dominação de uma classe social específica. ${ }^{9}$

Habermas considera que o quadro conceitual no interior do qual Marcuse trabalha (o qual reedita a antiga oposição marxiana entre o desenvolvimento das forças produtivas e o solapamento das relações de produção que proporcionaram inicialmente esse desenvolvimento) não é apto a dar conta da cisão existente na racionalidade técnico-científica. Mesmo tendo sido capaz de vislumbrar o problema definido pela transformação da racionalidade instrumental em racionalidade constituidora de um mundo da vida, “[ . . .] a forma racional da ciência e da técnica, isto é, a racionalidade materializada em sistemas de ação racional teleológica acaba por constituir uma forma de vida, uma 'totalidade histórica' de um mundo vital” (HABERMAS, 2006, p.55). Marcuse não desenvolveu o quadro categorial necessário para esclarecer o problema da técnica quando esta, rompendo os limites que a continham no plano de solução de problemas efetivamente técnicos, expande-se para esferas da vida social (quadro institucional) tradicionalmente produzidos e reproduzidos por um outro tipo de racionalidade não-instrumental.

8 Em trabalhos posteriores marcados por sua virada linguística, Habermas alterará essa leitura de uma interação puramente comunicativa, abrindo espaço para processos de interação mediados por uma lógica não comunicativa.

9 Habermas lembra-nos que em diversas passagens de sua obra OnedimensionalMan, Marcuse parece relativizar essa sua visão sobre a técnica e a ciência como expressões de um projeto histórico-político de classe. Nesse sentido, Marcuse reconheceria que a racionalidade que sustenta a técnica e a ciência manter-se-ia inalterada mesmo diante de uma transformação do quadro institucional que efetivasse a emancipação humana (Cf. (HABERMAS, 2006, p. 53 et seq.).

\begin{tabular}{|l|l|l|l|l|}
\hline Revista Dialectus & Ano 9 & n. 17 & Maio-Agosto 2020 & p.229-243 \\
\hline
\end{tabular}


O objetivo principal de Habermas, em seu ensaio Técnica e ciência como “ideologia”, é o de justamente oferecer um novo quadro conceitual mais adequado para a explicação desse fenômeno constitutivo das sociedades modernas no capitalismo tardio.

\section{O problema da técnica em Habermas}

Habermas afirma que o conceito de racionalização desenvolvido por Weber é produto de seu esforço para explicar as transformações institucionais advindas da passagem das sociedades tradicionais para a sociedade moderna. Weber interpreta a modernização como o alargamento dos subsistemas da ação racional teleológica que provoca transformações irreversíveis no quadro institucional das sociedades tradicionais. Habermas afirma, contudo, que o conceito weberiano da racionalização surge sob a égide da filosofia da subjetividade, o que limita significativamente suas possibilidades analíticas. Tendo em vista superar essas limitações e proporcionar uma análise mais adequada do significado da expansão da racionalidade técnico-científica para a transformação do quadro institucional das sociedades modernas no capitalismo tardio, Habermas lança mão das categorias trabalho e interação.

Habermas entende trabalho como sendo a ação racional teleológica, a qual engloba tanto a ação instrumental quanto a ação estratégica. No primeiro tipo de ação, o agente defronta-se com um mundo de objetos externos e independentes que ele manipula a partir de seu conhecimento empírico sobre a realidade. No segundo tipo, o agente defronta-se com um mundo social formado por outros indivíduos cujos comportamentos ele deseja influenciar visando alcançar seus objetivos egoístas. Em ambos os casos, o sucesso da ação é definido pelo êxito, ou seja, pela conquista dos fins previamente estabelecidos através da utilização dos meios disponíveis nas situações dadas. Por sua vez, a interação é constituída pela ação comunicativa, a qual exige a produção de um entendimento entre pelo menos dois sujeitos agentes que partilham uma linguagem cotidiana comum e expectativas de comportamento recíprocas derivadas de uma definição partilhada da situação. Na ação comunicativa, são normas de vigência obrigatória mutuamente reconhecidas pelos agentes que permitem a coordenação das ações e o processo interativo decorrente. Diferentemente das regras que sustentam a ação racional teleológica, que estão fundadas em um conhecimento verdadeiro ou

\begin{tabular}{|l|l|l|l|l|}
\hline Genista Dialectus & Ano 9 & n. 17 & Maio - Agosto 2020 & p.229-243 \\
\hline
\end{tabular}


analiticamente correto da realidade física ou social, as regras que sustentam a ação comunicativa dependem do reconhecimento intersubjetivo dos agentes envolvidos na interação. Uma violação das regras, no primeiro caso, leva ao fracasso perante a realidade; no segundo, a sanções que estão atreladas às regras por convenção. $\mathrm{O}$ domínio por parte de um agente das regras do primeiro tipo o dotam de habilidades necessárias para o sucesso no mundo empírico ou social; a internalização das regras do segundo tipo dota o indivíduo de estruturas da personalidade motivadoras de um comportamento em conformidade com as normas.

Diante das características intrínsecas a cada uma das espécies de ação descritas acima, Habermas considera que tais ações são irredutíveis uma à outra e cumprem funções completamente diferentes na sustentação da vida humana.

A distinção efetuada por Habermas entre esses dois tipos fundamentais de ação permite-lhe uma análise dos sistemas sociais constituidores de uma sociedade segundo o tipo de ação que neles se sobressaia.

\begin{abstract}
Servindo-nos dos dois tipos de ação, podemos distinguir os sistemas sociais segundo neles predomine a ação racional teleológica ou a interação. $\mathrm{O}$ enquadramento institucional de uma sociedade consta de normas que dirigem as interações linguisticamente mediadas. Mas há subsistemas, como o sistema econômico ou o aparelho estatal [. . . ] nos quais se institucionalizam sobretudo proposições acerca de ações racionais teleológicas [. . .] na esfera analítica, quero distinguir entre 1) o enquadramento institucional de uma sociedade ou de um mundo vital sociocultural, e 2) os subsistemas da ação racional relativa a fins que se 'incrustam' nesse enquadramento ${ }^{10}$ (HABERMAS, 2006, p. 60, grifos do autor).
\end{abstract}

A passagem referida mostra claramente que Habermas, em suas primeiras formulações acerca da relação entre o marco institucional de uma sociedade e os subsistemas organizados em torno da ação racional teleológica, já compreendida que estes últimos dependem do primeiro para poder existir. Isso se torna evidente na medida em que percebemos que os sentidos definidores dos fins a serem perseguidos (em alguns casos teleologicamente) são originalmente construídos no enquadramento institucional da sociedade, isto é, no âmbito do mundo da vida no qual predomina a racionalidade comunicativa. É exatamente do desequilíbrio dessa relação, oriundo da invasão dos espaços comunicativos pela racionalidade técnico-científica, ou seja, pela racionalidade instrumental-estratégica, que se originam as patologias que marcam as

10 Aqui é importante notarmos que Habermas em nenhum momento afirma que qualquer sistema ou subsistema social seja regido unicamente por um dos tipos de ação por ele identificados.

\begin{tabular}{|l|l|l|l|l|}
\hline Revista Dialectus & Ano 9 & n. 17 & Maio-Agosto 2020 & p.229-243 \\
\hline
\end{tabular}


sociedades modernas no capitalismo tardio. Habermas interpreta que a existência de ameaças contra a estabilidade e reprodução comunicativa do enquadramento institucional é inclusive a marca definidora e distintiva das sociedades que atingiram a modernidade.

\begin{abstract}
As sociedades 'tradicionais' só existem enquanto a evolução dos subsistemas da ação racional dirigida a fins se mantém dentro dos limites da eficácia legitimadora das tradições culturais. Isto origina uma 'superioridade' do marco institucional, superioridade que certamente não exclui reestruturações induzidas por um potencial excedente das forças produtivas, mas exclui sim a dissolução crítica da forma tradicional da legitimação. Semelhante inatacabilidade constitui um critério significativo para a demarcação das sociedades tradicionais, relativamente àquelas que atravessaram o limiar da modernização (HABERMAS, 2006, p. 62, grifos do autor).
\end{abstract}

O modo de produção capitalista foi o primeiro historicamente a desacoplar o desenvolvimento das forças produtivas do enquadramento institucional, o qual sempre desempenhou o papel de fornecedor das explicações legitimadoras da dominação vigente. O capitalismo, por tornar autônomo o processo de produção contínuo e cumulativo da riqueza material em relação à lógica comunicativa do enquadramento institucional, expande de forma crescente a influência da racionalidade teleológica do processo produtivo, ao ponto de abalar a relação tradicionalmente constituída entre os dois tipos de racionalidade contrapostos.

“[ . . .] o modo de produção capitalista pode conceber-se como um mecanismo que garante uma extensão permanente dos subsistemas da ação racional teleológica, abalando assim a 'superioridade' tradicionalista do enquadramento institucional perante as forças produtivas" (HABERMAS, 2006, p. 63, grifo do autor).

As cosmovisões tradicionais legitimadoras da dominação, que eram reproduzidas no quadro institucional na forma de comunicações distorcidas "por símbolos cindidos e motivos reprimidos" (HABERMAS, 2006, p.63), defrontam-se com uma outra forma de racionalidade que vincula meios a fins presente nos sistemas de ação regidos pela racionalidade teleológica. Para Habermas, esse confronto marca o fim da sociedade tradicional e de sua forma de legitimação da dominação.

Habermas aponta-nos que o capitalismo institui um novo tipo de legitimação da dominação. Esta deixa de ser política, como no caso da legitimação nas sociedades tradicionais, e passa a ser econômica, posto sustentar-se na ideia de que as trocas que se desenrolam na esfera da produção material se dão entre valores

\begin{tabular}{|l|l|l|l|l|}
\hline Gevista Dialectus & Ano 9 & n. 17 & Maio - Agosto 2020 & p.229-243 \\
\hline
\end{tabular}


equivalentes. A dominação política sustenta-se então não mais com apelo às tradições culturais, mas sim pela referência ao mecanismo econômico que estrutura o processo produtivo. Essa forma de legitimação econômica da dominação política possibilita a invasão dos espaços outrora restritos à ação comunicativa pela lógica instrumental e estratégica presente nos subsistemas da ação racional teleológica. ${ }^{11}$

Habermas denomina esse processo de "racionalização a partir de baixo”, isto é, uma racionalização que se desenrola no âmbito infraestrutural da sociedade. A esse processo de racionalização infraestrutural, Habermas contrapõe um outro complementar a "partir de cima" ou superestrutural, o qual deslegitimando as tradições sustentadoras da dominação por meio da imposição de critérios oriundos da racionalidade teleológica substituem-nas por novas legitimações que se pretendem científicas, haja vista fundarem-se na mesma racionalidade subjacente à ciência moderna. Mantêm, contudo, a mesma função ideológica das antigas legitimações tradicionais que substituem por mascararem as relações de poder existentes imunizandoas contra críticas.

Essa configuração entre quadro institucional e subsistemas da ação racional teleológica foi característica do período liberal do capitalismo, no qual a atividade econômica desenvolvida na sociedade através de trocas privadas reguladas pelo direito burguês desenrolava-se com relativa independência em relação à intervenção estatal. Foi por isso que a crítica de Marx à ideologia pôde se apresentar na forma de uma crítica à economia política, haja vista que a legitimação da dominação política deixara de ser imediatamente política e passara a ser econômica. Marx realizou sua crítica por meio do desvelamento da estrutura de exploração e sujeição presente nas relações de produção capitalista e encoberta pela instituição jurídica burguesa do contrato de trabalho livre celebrado entre iguais na esfera do mercado.

[Marx] Levou a cabo a crítica da ideologia burguesa na forma da economia política: a sua teoria do valor-trabalho destruiu a aparência da liberdade com que a instituição jurídica do livre contrato de trabalho tornara irreconhecível a violência social subjacente à relação do trabalho assalariado (HABERMAS, 2006, p. 67, grifos do autor).

11 "Habermas está afirmando [. . .] que as patologias específicas do capitalismo contemporâneo surgem à medida em que os meios do dinheiro e do poder se infiltram cada vez mais em esferas da vida social nas quais tradições e conhecimento são transferidos, laços normativos são de modo intersubjetivo estabelecidos e pessoas responsáveis são formadas" (WHITE, 1995, p.110).

\begin{tabular}{|l|l|l|l|l|}
\hline Ronita Dialectus & Ano 9 & n. 17 & Maio-Agosto 2020 & p.229-243 \\
\hline
\end{tabular}


Essa crítica marxiana deixa de ser adequada, contudo, a partir do momento em que: a) o Estado abandona o seu antigo papel de mero garantidor da ordem e do cumprimento dos contratos e passa a intervir ativamente no funcionamento do processo econômico com o objetivo de assegurar sua reprodução, expansão e estabilidade; e b) a ciência e a técnica transformam-se "na primeira força produtiva" do sistema capitalista. A dominação volta a adquirir assim um caráter político fundamental. Sua legitimação, contudo, não pode ser feita pelo simples retorno às formas tradicionais de legitimação do poder político, pois os mitos, as cosmovisões e as metafísicas unificadores perderam seu poder de convencimento e aglutinação. "A dominação em termos de democracia formal, própria dos sistemas do capitalismo regulado pelo Estado, encontra-se sob uma necessidade de legitimação, que já não pode resolver-se pelo recurso à forma préburguesa de legitimação" (HABERMAS, 2006, p.70).

Habermas defende que a legitimação vem agora na forma de um programa substitutivo que consegue a cooptação das massas através da correção das disfunções do sistema econômico e do estabelecimento de compensações sociais contra os riscos inerentes à forma privada de valorização do capital. Nesse sentido, o sistema de dominação política alcança a adesão social por meio do estabelecimento de um Estado de bem-estar social, o qual, por sua vez, expulsa da esfera política os temas práticos historicamente a esta vinculados, desidratando-os até ao ponto de torná-los questões simplesmente técnicas de ajustamento do sistema.

A atividade estatal (política) é restringida à resolução administrativa de problemas técnicos. São excluídas as discussões práticas da atividade política. Esta deixa de tematizar as questões sobre a determinação da vida boa e de como a sociedade deveria organizar-se em função do alcance coletivo de valores como, por exemplo, liberdade, igualdade, fraternidade e felicidade humanas. A política passa a ser entendida apenas como mecanismo voltado à solução de dificuldades técnicas de organização do sistema, tendo em vista a manutenção de sua estabilidade e reprodução. A crítica em si ao sistema, o questionamento se este realiza ou não aqueles valores práticos são neutralizados quando a política é subjugada à técnica. ${ }^{12}$

12 “[. . . Habermas critica o avanço incessante da ciência e da racionalidade técnico-científica, que 'rebaixa' questões altamente políticas relacionadas com a regulação racional da vida comunitária da sociedade - questões que deveriam ser debatidas entre os cidadãos - e as transforma em meros problemas técnico-racionais; segundo ele, isso pode significar a substituição do debate político pelo governo de especialistas" (JOAS; KNÖBL, 2017, p. 237-238).

\begin{tabular}{|l|l|l|l|l|}
\hline Revista Dialectus & Ano 9 & n. 17 & Maio-Agosto 2020 & p.229-243 \\
\hline
\end{tabular}


Contudo, apesar desse avanço da lógica tecnicista sobre as questões práticas, estas não são efetivamente eliminadas, o que institui uma tensão crucial entre o quadro institucional e os subsistemas da ação racional com relação a fins. A necessidade de legitimação da dominação política sob tais circunstâncias é satisfeita através da despolitização das massas levada a cabo com a participação central da ciência e da técnica, as quais assumem então uma função ideológica evidente, como diria Marcuse.

\begin{abstract}
A eficácia peculiar desta ideologia reside em dissociar a autocompreensão da sociedade do sistema de referência da ação comunicativa e dos conceitos da interação simbolicamente mediada, e em substituí-lo por um modelo científico. Em igual medida, a autocompreensão culturalmente determinada de um mundo social da vida é substituída pela autocoisificação dos homens, sob as categorias da ação racional dirigida a fins e do comportamento adaptativo (HABERMAS, 2006, p.74).
\end{abstract}

Essa nova configuração de forças em conflito, caracterizada pela forte influência da lógica tecnicista sobre a compreensão coletiva acerca do que seja importante para o desenvolvimento do sistema social, ou seja, a aceitação psicossocial de que a evolução do sistema social se dá pela resolução de problemas técnicos conquistada pela expansão da racionalidade teleológica para todas as esferas da vida social, essa nova configuração de forças ameaça dissolver, a longo prazo, o próprio enquadramento institucional regido pela ação comunicativa e que tradicionalmente ancorou o desenvolvimento dos subsistemas que agora o dissolvem. "O enquadramento institucional da sociedade, que até agora foi sustentado por um outro tipo de ação, seria agora [. . .] absorvido pelos subsistemas da ação racional teleológica, que nele estão incrustados" (HABERMAS, 2006, p.75).

A ideologia então assume as feições de uma consciência tecnocrática que torna indistinguíveis as duas esferas de ação que proporcionaram o desenvolvimento das sociedades humanas ao longo da história da espécie. "A força ideológica da consciência tecnocrática verifica-se no ocultamento de semelhante diferença" (HABERMAS, 2006, p.76). A consciência tecnocrática, entretanto, não deve ser identificada com o conceito de ideologia desenvolvido por Marx de maneira imediata. Apesar de ainda poder ser vinculada aos interesses de dominação de uma determinada classe e, dessa forma, reprimir a emancipação de outra, a consciência tecnocrática vai além, pois afeta "o interesse emancipador como tal do gênero humano" (HABERMAS, 2006, p. 80). A consciência tecnocrática não assume, como outrora as ideologias analisadas por Marx, a forma de uma falsa consciência que possa ser desmascarada pela reflexão na forma de

\begin{tabular}{|l|l|l|l|l|}
\hline Gevista Dialectus & Ano 9 & n. 17 & Maio - Agosto 2020 & p.229-243 \\
\hline
\end{tabular}


uma crítica à ideologia. ${ }^{13}$ A consciência tecnocrática expulsa do âmbito das relações comunicativas a necessidade de legitimação da dominação, pois o sistema de controle e sujeição é tido agora como expressão de uma lógica neutra das coisas interligadas por meio do sistema. A consciência tecnocrática, portanto, elimina do âmbito da interação a necessidade de uma justificação política das relações sociais vigentes.

[. . .] a nova ideologia distingue-se das antigas pelo fato de separar os critérios de justificação da organização da convivência, portanto, das regulações normativas da interação em geral e, nesse sentido, os despolitizar e, em vez disso, os vincular às funções de um suposto sistema de ação racional dirigida a fins (HABERMAS, 2006, p.81).

A consciência tecnocrática suprime a comunicação livre como instância de produção de sentidos normativos mutuamente vinculantes indispensáveis para a interação entre os indivíduos, abalando dessa forma "[. . .] uma das duas condições fundamentais da nossa existência cultural [ . . .]" (HABERMAS, 2006, p.82).

Habermas, diante de sua articulação teórica das categorias trabalho e interação, considera inadequada para a explicação do processo de desenvolvimento e transformação das sociedades humanas, a rede categorial desenvolvida por Marx no materialismo histórico, a qual identificava uma tensão dialética fundamental entre forças produtivas e relações de produção. Esta apontava, como sabemos, para o potencial emancipatório contido no desenvolvimento das forças produtivas na medida em que elas ocasionavam a transformação das relações de produção.

O par conceitual trabalho/interação torna evidente que o desenvolvimento das forças produtivas, isto é, dos subsistemas regidos pela racionalidade teleológica (em termos habermasianos), não leva necessariamente à emancipação humana como parecia supor Marx, antes, tão logo se tornam a principal força produtiva, podem cumprir o papel de elementos legitimadores da dominação.

\section{Considerações finais}

13 White identifica a necessidade de substituição da crítica à ideologia pela crítica do empobrecimento cultural: “[. . .] a 'crítica de ideologia' tradicional perde sua base, visto que dependia de partir dos ideais positivos projetados dentro de uma ideologia. A crítica da ideologia neste sentido tem de ser substituída pela crítica do empobrecimento cultural e fragmentação da consciência cotidiana. E para esta tarefa, o modelo comunicativo e a ideia associada do potencial racional da modernidade fornecem a base crítica. Estas concepções em conjunto dão a Habermas um ponto de vista abrangente do qual ele pode dar substância à sua ideia de 'distorções sistemáticas de comunicação'. O que deve ser explicado sob esta rubrica é como a organização do conhecimento e deliberação prática na sociedade contemporânea sistematicamente solapam o potencial de um mundo da vida racionalizado" (WHITE, 1995, p. 114-115).

\begin{tabular}{|c|c|c|c|c|}
\hline Qevista Dialectus & Ano 9 & n. 17 & Maio - Agosto 2020 & p.229-243 \\
\hline
\end{tabular}


Habermas, em sua explicação da "evolução sociocultural da espécie", identifica um descompasso entre dois tipos fundamentais de adaptação: uma ativa, determinada pela submissão dos processos naturais às necessidades humanas, conquistada por meio da ação instrumental que amplia de forma constante nosso poder de disposição técnica sobre a natureza, e uma adaptação passiva do quadro institucional às transformações oriundas das conquistas da ação racional teleológica, em uma palavra: do trabalho.

Habermas concebe que a grande tarefa emancipadora das sociedades humanas é superar essa adaptação passiva do marco institucional, tornando-a produto de decisões conscientes, isto é, tornando-a uma adaptação ativa. Alerta-nos, contudo, que isso não pode ser conquistado através da invasão do enquadramento institucional pela lógica inerente aos subsistemas da ação racional em relação a fins, pois tal colonização equivaleria à realização de uma distopia e não à produção de uma sociedade mais humana. A lógica inerente à racionalidade estratégico-instrumental é uma lógica da coisificação e não da humanização. Não é a ampliação da disposição técnica sobre os espaços tradicionalmente reservados à racionalidade comunicativa - que veda, por sua própria lógica, a objetificação do outro, instituindo o reconhecimento mútuo e o acordo racionalmente motivado como pressupostos incontornáveis - que possibilitará ao ser humano enquanto espécie a construção consciente de uma sociedade emancipada.

A argumentação desenvolvida por Habermas em seu ensaio Técnica $e$ ciência como 'ideologia', portanto, procura fundamentar a nível categorial por que o mero desenvolvimento técnico-científico, caracterizado por um crescente poder de disposição técnica sobre a natureza e a sociedade, não equivale à construção de uma sociedade humanamente melhor, isto é, de uma sociedade apta a efetivar valores como, por exemplo, felicidade, justiça e solidariedade humanas. Ciência e técnica podem sim, em princípio, ser utilizadas para a construção de uma sociedade utópica, desde que saibamos diferenciar os dois tipos fundamentais de racionalização e subordinemos os fins externos da técnica e da ciência aos valores construídos comunicativamente em uma sociedade formada por indivíduos progressivamente livres e emancipados.

\section{REFERÊNCIAS}

CHAGAS, E. Reflexão sobre a técnica em Marx. In: MAIA, A. (org.). Técnica e existência: ensaios filosóficos. Sobral: Caminhar, Edições Universitárias - UVA, 2012. p. 137-156.

\begin{tabular}{|c|c|c|c|c|}
\hline Rovista Oialectus & Ano 9 & n. 17 & Maio - Agosto 2020 & p.229-243 \\
\hline
\end{tabular}


DINIZ, F. Técnica e legitimação em Habermas: passos e descompassos. In: MAIA, A. (org.). Técnica e existência: ensaios filosóficos. Sobral: Caminhar, Edições Universitárias - UVA, 2012. p. 235-253.

HABERMAS, J. Técnica e ciência como “ideologia”. Lisboa: Edições 70, 2006.

JOAS, H.; KNÖBL, W. Teoria social: vinte lições introdutórias. Petrópolis: Vozes, 2017.

OLIVEIRA, R. Homem, ciência e técnica: um mapa filosófico-antropológico da contemporaneidade. In: MAIA, A. (org.). Técnica e existência: ensaios filosóficos. Sobral: Caminhar, Edições Universitárias - UVA, 2012. p. 61-73.

PUENTES, Fernando Rey. A téchne em Aristóteles. Hypnos: téchne, São Paulo, ano 3, n. 4, p. 129-135, 1998.

SILVA, R.; SILVA, N. Técnica e política: considerações. In: MAIA, Antônio Glaudenir Brasil (org.). Técnica e existência: ensaios filosóficos. Sobral: Caminhar, Edições Universitárias - UVA, 2012. p. 77-91.

WHITE, S. Razão, justiça e modernidade: a obra recente de Jürgen Habermas. São Paulo: Ícone, 1995. 